\title{
Setting the Standards: Examining Research Productivity Among Academic Urologists in the USA and Canada in 2019.
}

\author{
Thenappan Chandrasekar \\ Thomas Jefferson University \\ Timothy M. Han \\ Thomas Jefferson University \\ Lydia Glick \\ Thomas Jefferson University \\ Joon Yau Leong \\ Thomas Jefferson University \\ Follow this and additional works at: https://jdc.jefferson.edu/urologyfp \\ f-th Teplitsky \\ Inomas Jefferson University ${ }^{\text {. }}$ \\ Let us know how access to this document benefits you
}

\section{See next page for additional authors}

Recommended Citation

Chandrasekar, Thenappan; Han, Timothy M.; Glick, Lydia; Leong, Joon Yau; Teplitsky, Seth;

Noorani, Rodrigo; Goldberg, Hanan; Klaassen, Zachary; Wallis, Christopher J.D.; Mark, James R.; Trabulsi, Edouard J.; Lallas, Costas D.; and Gomella, Leonard G., "Setting the Standards:

Examining Research Productivity Among Academic Urologists in the USA and Canada in 2019." (2020). Department of Urology Faculty Papers. Paper 56.

https://jdc.jefferson.edu/urologyfp/56

This Article is brought to you for free and open access by the Jefferson Digital Commons. The Jefferson Digital Commons is a service of Thomas Jefferson University's Center for Teaching and Learning (CTL). The Commons is a showcase for Jefferson books and journals, peer-reviewed scholarly publications, unique historical collections from the University archives, and teaching tools. The Jefferson Digital Commons allows researchers and interested readers anywhere in the world to learn about and keep up to date with Jefferson scholarship. This article has been accepted for inclusion in Department of Urology Faculty Papers by an authorized administrator of the Jefferson Digital Commons. For more information, please contact: JeffersonDigitalCommons@jefferson.edu. 


\section{Authors}

Thenappan Chandrasekar, Timothy M. Han, Lydia Glick, Joon Yau Leong, Seth Teplitsky, Rodrigo Noorani, Hanan Goldberg, Zachary Klaassen, Christopher J.D. Wallis, James R. Mark, Edouard J. Trabulsi, Costas D. Lallas, and Leonard G. Gomella 


\section{European Urology Focus}

\section{Setting the Standards: Examining Research Productivity amongst Academic Urologists in the United States and Canada in 2019 \\ --Manuscript Draft--}

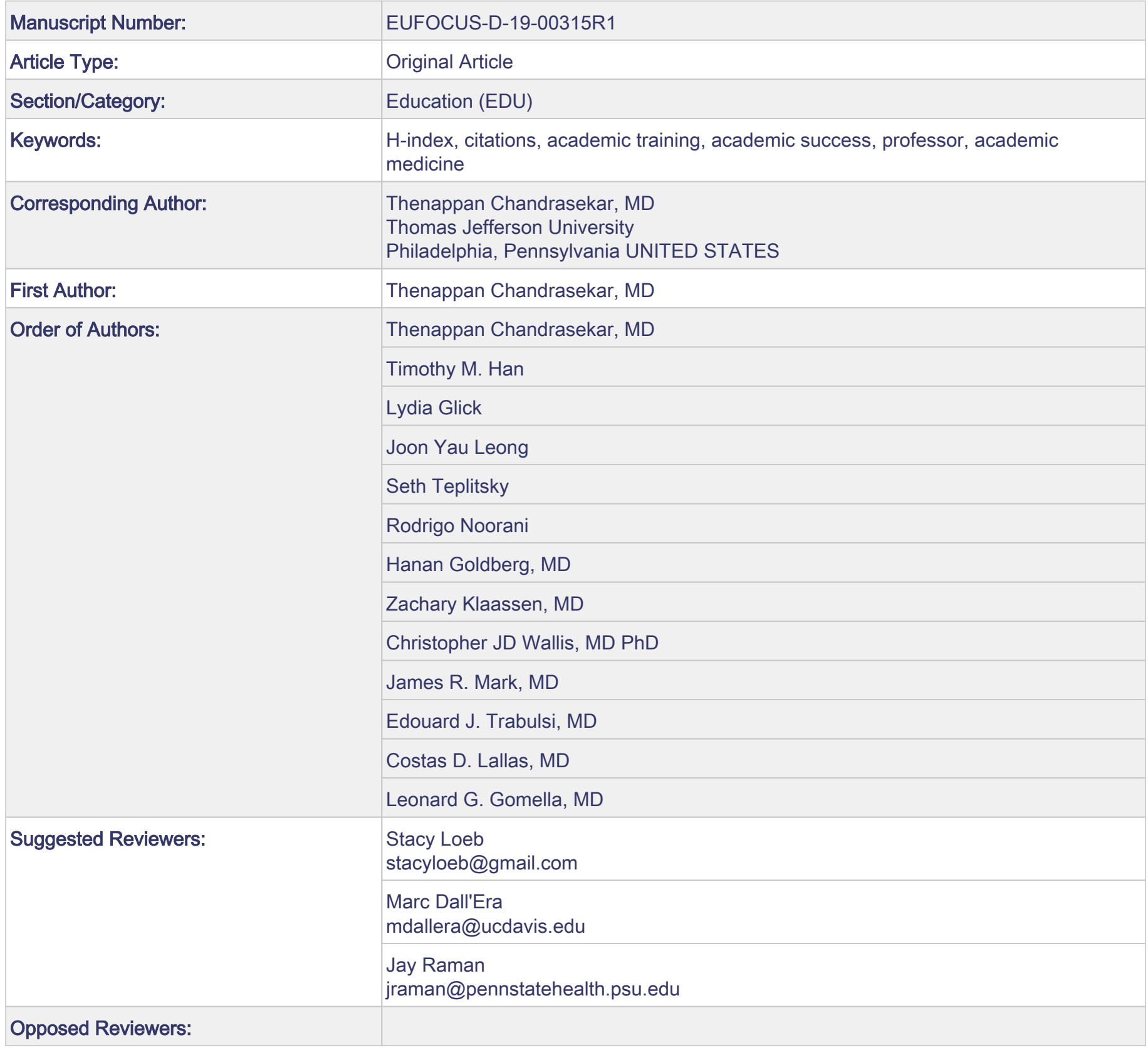


Click here to access/download

\section{Authorship Form EUFauthorshipform2018.doc}


Title: Setting the Standards: Examining Research Productivity amongst Academic Urologists in the United States and Canada in 2019

Running Title: Research Productivity and Academic Urology 2019

Authors: Thenappan Chandrasekar ${ }^{1}$, Timothy M. Han ${ }^{1}$, Lydia Glick ${ }^{1}$, Joon Yau Leong ${ }^{1}$, Seth Teplitsky ${ }^{1}$, Rodrigo Noorani ${ }^{2}$, Hanan Goldberg ${ }^{3}$, Zachary Klaassen ${ }^{4}$, Christopher JD Wallis ${ }^{5}$, James R. Mark ${ }^{1}$, Edouard J. Trabulsi ${ }^{1}$, Costas D. Lallas ${ }^{1}$, Leonard G. Gomella ${ }^{1}$ Affiliation:

1. Department of Urology, Sidney Kimmel Cancer Center, Thomas Jefferson University, Philadelphia, PA

2. Division of Urology, Department of Surgery, University of Toronto, Toronto, ON, Canada

3. Department of Urology, State University of New York Upstate Medical University, Syracuse, NY, USA

4. Division of Urology, Department of Surgery, Augusta University - Medical College of Georgia, Augusta, GA; Georgia Cancer Center, Augusta, GA

5. Department of Urology, Vanderbilt University Medical Center, Nashville, TN, USA

Corresponding Author:

Thenappan Chandrasekar, MD

Department of Urology, Thomas Jefferson University

1025 Walnut Street, Suite 1100

Philadelphia PA 19107

United States

Phone: 732-742-1025

Fax: 844-351-9508

Email: thenappan.chandrasekar@gmail.com

Funding Source: None

Conflicts of Interest: All authors report no COI

Article Type/Category: Original Article

Summary

Word Count (Manuscript): 2587

Word Count (Abstract): 299

Tables: 3

Figures: 2 
Author Contribution:

1) TC: Conceptualization, Data Curation, Formal Analysis, Writing (Original, Review \& Editing)

2) TMH, LG, JYL, ST, RN: Formal Analysis, Writing (Review \& Editing)

3) CJDW, ZK, HG, CDL, JRM, EJT, LGG: Resources \& Supervision 


\section{STRUCTURED ABSTRACT}

Background: Research productivity amongst academic urologists is strongly encouraged, but little data is available on productivity metrics within the field.

Objective: To provide the first comprehensive survey of research productivity amongst academic urologists in the United States and Canada.

Methods: Using the Accreditation Council for Graduate Medical Education (ACGME), the Canadian Resident Matching Service (CaRMS) and individual program websites, all active accredited urology faculty were identified. For each individual, we collected data on AUA section, title, gender, fellowship training, Scopus H-index and citations. Comprehensive searches were completed during March-May 2019.

Statistical Analysis: Descriptive statistics for demographic comparisons were performed using analysis of variance (ANOVA) for continuous variables and chi-square test for categorical variables. Multivariable logistic regressions were used to identify predictors of $\mathrm{H}$-index greater than the median.

Results: 2214 academic urology faculty (2015 USA, 199 Canada) were identified. Median and mean $\mathrm{H}$-index for the entire cohort of physicians was 11 and 16.1, respectively. On multivariable analysis, physicians in the North Central and Western Sections (vs. Mid-Atlantic), who were fellowship-trained (vs. no fellowship training), and of higher academic rank (Professor and Associate Professor vs. clinical instructor) were more likely to have H-index values greater than the median. Additionally, female physicians (vs. male) were more likely to have H-index values less than the median.

Conclusion: This study represents the first comprehensive assessment of research productivity metrics amongst academic urologists. These represent key benchmarks for trainees considering 
careers in academics and for practicing physicians gauging their own productivity in relation to their peers.

Patient Summary: In this study, we provide the first comprehensive assessment of research productivity amongst academic urologists in the United States and Canada. Our results help provide key benchmarks for trainees considering careers in academics and for practicing physicians gauging their own productivity in relation to peers. 


\section{INTRODUCTION}

Research productivity has been strongly encouraged within the realm of academic medicine. Many centers incorporate research productivity into established clinical tracks for academic promotion. For younger physicians who are new to academia, it can prove challenging to assess one's own research contributions and output in the context of their given specialty and practice. Historically and most simply, the number of publications and their citations have served as the cornerstone of assessing research productivity and impact. However, these raw values are limited in characterizing an individual's research presence as higher numbers do not necessarily represent the quality and impact of publications. As a result, various other metrics have arisen to help characterize and quantify research achievement and output. In 2005, Hirsch described and proposed the h-index as a tool to address some of these limitations (1). Defined as the $h$ number of papers with $\geq h$ citations each, the $h$-index may serve as a useful yardstick in assessing and quantifying scientific achievement (1) by minimizing some of the biases that were seen with using raw number of publications and/or citations as a metric.

The h-index has been used across multiple medical and surgical specialties and has been found to have a strong association with academic productivity and academic standing (2-12). However, there is little data available on these productivity metrics within the field of urology. In 2008, Benway et al. found a strong association between h-index and academic standing by performing a single-day web search of the top 20 academic urology programs (U.S. News and World Report 2008 rankings) (13). Since then, there has been no data further exploring this association and its implications within academic urology. In this study, we aim to provide the first comprehensive survey of research productivity amongst all academic urologists in the United States and Canada in 2019. 


\section{METHODS}

\section{$\underline{\text { Population and Demographics }}$}

Comprehensive searches were completed for all academic urology programs and physicians during March-May 2019 by using the Accreditation Council for Graduate Medical Education (ACGME) (14), the Canadian Resident Matching Service (CaRMS) (15) and individual program websites. For each of these programs in the United States and Canada, state (if located in the USA), American Urologic Association (AUA) section, and resident class size were recorded. Within these programs, academic urology faculty were identified and catalogued by crossreferencing all available institutional and hospital data. For each individual urologist, gender, academic title, fellowship training and type(s), and AUA section were documented. Academic productivity was characterized by $\mathrm{H}$-index and citations, as per Scopus records (April-May 2019).

\section{$\underline{\text { Statistical Analysis }}$}

Descriptive statistics for demographic comparisons were performed using analysis of variance (ANOVA) for continuous variables and chi-square test for categorical variables. Multivariable logistic regressions were used to identify predictors of $\mathrm{H}$-index greater than the median (> 11). All statistical tests were two-tailed and a p-value of $<0.05$ was considered statistically significant. Analyses were completed using SPSS®, version 23.0. 


\section{RESULTS}

\section{$\underline{\text { Demographics }}$}

Through comprehensive search using the ACGME, CaRMS, and individual academic urology program data, 2214 academic urology faculty (2015 USA, 199 Canada) were identified. Demographics of academic urologists, stratified by academic position, are summarized in Table 1. The majority of academic urologists were Assistant Professors (38.0\%); the remaining were primarily Associate Professors (22.4\%) or full Professors (25.8\%), with a small proportion being Clinical Instructors (2.3\%). 252 (11.4\%) of the academic urologists had unlisted academic positions. On univariate analysis, a greater proportion of academic urologists in the USA $(\mathrm{p}=0.033)$, male urologists $(\mathrm{p}<0.001)$, and fellowship-trained urologists $(\mathrm{p}=0.01)$ were likely to be of higher academic title/position.

$\underline{\text { H-index distribution }}$

H-index was catalogued for each physician when available; for the entire cohort, the calculated median $\mathrm{H}$-index was 11 and the mean was 16.1. Figure 1 depicts the distribution of $\mathrm{H}$-indices for academic urologists in North America. Figure 2 shows the distribution of $\mathrm{H}$-indices when matched to each individual urologist's number of citations, demonstrating a strong correlation between number of citations and $\mathrm{H}$-index.

$\underline{\text { Univariate analysis of median } \mathrm{H} \text {-index stratified by academic title }}$

Table 2 summarizes median $\mathrm{H}$-indices as stratified by academic title. First, there is a significant step-wise increase in the median $\mathrm{H}$-index with academic promotion, from 5 for Clinical Instructors to 29 for Professors $(\mathrm{p}<0.001)$. Median H-indices tended to be higher in the North Central and New England AUA Sections and lower in the South Central and Southeastern AUA sections $(\mathrm{p}<0.001)$. Higher median H-indices were also identified among Canadian academic 
urologists $(\mathrm{p}<0.001)$, male academic urologists $(\mathrm{p}<0.001)$, and physicians with fellowship training ( $\mathrm{p}<0.001)$, specifically in Urologic Oncology, MIS/Robotics or multiple fellowships. Predictors of higher H-index and academic productivity

Multivariate logistic regression analysis was performed to identify predictors of higher academic productivity, defined as an $\mathrm{H}$-index greater than the median $(\mathrm{H}$-index $>11)$. When compared to the Mid-Atlantic AUA Section, the North Central (OR 1.75, 95CI 1.15-2.67, p<0.01) and Western (OR 1.56, 95CI 1.02-2.40, $\mathrm{p}=0.04)$ Sections were more likely to have $\mathrm{H}$-index values greater than the median. Physicians who were fellowship-trained (vs. no fellowship training: OR 3.44, 95CI 2.56-4.63, $\mathrm{p}<0.01$ ) and physicians of higher academic rank (vs. clinical instructor: Associate Professor [OR 4.59, 95CI 2.17-9.68, p<0.01], Professor [OR 30.17, 95CI 13.88-65.54, $\mathrm{p}<0.01]$ ) were also more likely to have $\mathrm{H}$-index values $>11$. Female physicians (vs. male: OR $0.34,95 \mathrm{CI} 2.56-4.63, \mathrm{p}<0.01)$ were more likely to have $\mathrm{H}$-index values less than the median. There was no statistically significant association between country and H-index. 


\section{DISCUSSION:}

Through this assessment of all academic urology programs in the US and Canada, we provide the first comprehensive evaluation of academic productivity within academic Urology. In contrast to the study of Benway et al. (13), which was limited to the top 20 programs (by U.S. News and World Report 2008 rankings), we examined all academic urology programs with associated residency programs, thereby providing a comprehensive assessment of academic urology programs.

Benway et al. demonstrated a close association between H-index and academic position (13). In our assessment of all academic urology programs and their 2214 academic urology faculty (2015 USA, 199 Canada), we validated their findings. On multivariable analysis, physicians of higher academic rank were more likely to have higher $\mathrm{H}$-indices; however, this only applied to Professors and Associate Professors. While our dataset did not capture age, academic title may serve as a surrogate for physician age. However, it should be noted that the title of Assistant Professor was the most common academic position in the entire cohort, representing 38.0\% (841/2214) of all physicians. Within academic medicine, it is not uncommon for Assistant Professors to include both new faculty with great interest in academic productivity and older faculty who were primarily clinically focused and did not pursue promotion. Hence, this group likely represented a much wider age range, and may account for why the median H-index did not seem to significantly rise until Associate Professor status was reached.

Beyond academic title, fellowship training appears to be an important predictor of academic output. Fellowship trained physicians were 3.44 times more likely to have an H-index greater than the median (H-index > 11). Interestingly, our findings of the impact of fellowship training on academic productivity conflicts with prior studies. In 2014, Kasabwala et al. looked at 851 
faculty members from 101 academic urology departments and found no statistical difference in h-index between fellowship-trained and non-fellowship-trained academic urologists (16). Certain factors may contribute to these differences. First, as seen in Table 1, 21.9\% (232/1058) of all Associate Professors and Professors are not fellowship trained. Historically, clinical fellowship training was not as predominant as it is now, nor was it considered a pre-requisite for academic advancement. Hence, many senior academic urologists did not have formal fellowship training yet still advanced academically. Therefore, incorporation of these individuals may skew the results in favor of non-fellowship trained physicians, particularly in older studies. Our study, done more than 5 years later, may be better reflective of clinically active non-retired physicians. It is also possible that with a larger sample size of physicians (2214 vs. 851 ) and programs (156 vs. 101), our data represented a better cross-section of the field. Regardless, this relationship between fellowship-training and $\mathrm{H}$-index warrants further exploration, specifically as it may reflect and affect trainees' decision to enter the academic sector after residency. In 2011, Freilich et al. conducted a survey of residents revealing that the "most important" factors influencing the pursuit of urology fellowship were intellectual appeal (82\%), mentorship opportunities (79\%), the desire for an additional point of view for surgical training (58\%), and the desire to pursue and a career in academia (52\%) (17). Additionally, the survey revealed that urologists who publish (first author or co-author) while in residency were roughly 6 times more likely to pursue fellowship training (17). As a result, it would appear that those individuals who currently choose to pursue fellowship training are self-selected, as those who are likely to pursue academic medicine work towards publishing during training and in subsequent practice. Yang et al. demonstrated that increased research publication output during residency correlated with increasing dedicated research time and was associated with the pursuit of fellowship training and 
a career in academia (18). As residency training continues to be shortened, sometimes at the expense of dedicated research, future prospective studies are needed to evaluate the impact of reduced dedicated research time on academic productivity during residency, and the decision to pursue fellowship training and academic careers, especially as academic careers increasingly emphasize productivity metrics.

Lastly, in our study, we did note that female gender was independently associated with less than median $\mathrm{H}$-index values $(\mathrm{H}$-index $\leq 11)$. This contributes to the growing body of literature within medicine exploring potential gender disparities in the academic sector $(5-7,10-12,19-22)$. In a study from 2007 at Mayo Clinic, Reed et al. discovered that while women held fewer leadership roles throughout their careers $(\mathrm{p}<0.001)$, their publication rates increased and actually exceeded those of men in the latter stages of their careers (19). This unique productivity curve was again demonstrated among otolaryngology departments; while female physicians had lower research output earlier in their careers, their research output equaled or exceeded research productivity of men at more senior levels (10). Additionally, research output was found to be equal between men and women at higher academic ranks in the fields of gynecologic oncology (7), gastroenterology (12), dermatology (11), and neurologic surgery (6). Within urology, the existing literature suggests similar trends and gender disparities. Yang et al. showed that despite there being a higher proportion of women than men who pursued fellowship training and ultimately decided upon an academic career, female urology residents produced fewer total publications than men (p $=0.01)$, with fewer as first author $(\mathrm{p}=0.03)$ than men $(20)$. Furthermore, among trainees who pursued academia, a higher proportion of men $(\mathrm{p}=0.01)$ obtained Associate vs Assistant Professor rank (20). Mayer et al. showed that while male urologists had higher median H-indices than women overall $(\mathrm{p}<0.05)$ and higher academic ranks $(\mathrm{p}<0.05)$, there was no difference 
between genders in research productivity by successive rank after controlling for career duration (m-quotient) (21). It is clear that within the field of academic urology and medicine as a whole, implicit biases may exist favoring male physicians. In a study by Pololi et al. looking at a stratified random sample of 4578 full-time faculty (53\% female respondents), female faculty reported a lower sense of belonging and relationships within the workplace $(p<0.01)$, lower selfefficacy for career advancement $(\mathrm{p}<0.001)$, lower perceived gender equity $(\mathrm{p}<0.001)$, and lower belief that their respective institutions were making changes to address diversity goals ( $\mathrm{p}<$ 0.001) (22). Therefore, although women continue to represent a growing proportion of academic medicine, within and beyond urology, more efforts should be put forth to further elucidate these gender disparities and ultimately to address them effectively.

In further elucidating the academic research productivity landscape within urology, the positive role of social media needs to be discussed. Twitter and other forms of social media engagement continues to rise within urology and allows for rapid and easy dissemination of research ideas and collaboration opportunities. We recently noted in a comprehensive analysis of the Twitterverse amongst academic urologists and programs in North America that there exists an important association between academic productivity and Twitter utilization and metrics (23). Multivariable analysis performed in that study showed that physicians with higher $\mathrm{H}$-indices were more likely to have an individual Twitter account $(\mathrm{p}<0.01)$, however number of citations did not demonstrate the same association. While no causal relationship can be demonstrated, Twitter social media activity may help drive urologic academic productivity and serves as a useful resource and tool to help advance the field.

This study is not devoid of limitations. First, as the capture of program and physician metrics and Scopus academic metrics were manual, there is the potential for incomplete capture. In Scopus, 
many physicians had multiple listings due to prior academic affiliations, which were collated when identifiable. Additionally, there is the possibility that some urologists, and in particular female urologists, may have taken on a married name, leading to potential non-capture of research output. Ultimately, however, as an extensive effort was made to thoroughly perform these web searches using multiple key words, name combinations, and as most physicians were identified on Scopus, the authors are confident that the capture rate was quite high. Second, the use of the h-index as a valid tool has been criticized in published data (1, 24-30-) and must be weighed against the strength of the associations and conclusions drawn in this study. Our study also did not include data on the raw number of publications for each academic urologist, which may serve as an additional metric for productivity. However, the authors feel that assessing citations and h-index together carries similar weight and provides valuable insight into the urological research landscape. Finally, it is challenging to measure an academic urologist's contributions to a department merely using h-index or academic productivity, as his/her role within the department is complex, consisting of various metrics including research output, teaching, surgical skill, clinical acumen, and other responsibilities. In a study performed within a radiology department in 2000, Eschelman et al. found that faculty members with higher levels of clinical productivity (measured by the number of total professional relative value units generated) showed significantly lower levels of academic productivity (determined by number of published articles, abstracts, and presentations) (31). Therefore, it is difficult to distill an academic urologists' contributions down to one metric focused specifically on research output (h-index). Furthermore, opportunities for career advancement and promotion within academic urology are not always dependent on one's research output. For those in academic tracks with a 
focus outside of research, such as those stressing education, comparisons to an h-index benchmark may not be as meaningful. 


\section{CONCLUSION}

There is a paucity of literature and current data for trainees and staff to gauge their own productivity as they enter clinical practice following urology residency. This study represents the first comprehensive assessment of research productivity metrics amongst academic urologists. This data are not meant to serve as a criterion in assessing academic urologists interested in career advancement and promotion, but rather to help provide key benchmarks for trainees considering careers in academics and for practicing physicians gauging their own productivity in relation to their peers. The reality is that most academic urologists have $\mathrm{H}$-indices closer to 10 or lower (mean 16.1, median 11), which can be reassuring for younger urologists finishing up training. However, the climb from assistant to associate professorship and beyond becomes much steeper, and these benchmarks can help create a better understanding of that landscape. 


\section{REFERENCES / BIBLIOGRAPHY}

1. Hirsch JE. An index to quantify an individual's scientific research output. Proceedings of the National Academy of Sciences of the United States of America. 2005 Nov $15 ; 102(46): 16569-72$.

2. Susarla SM, Rada EM, Lopez J, Swanson EW, Miller D, Redett RJ, Kumar AR. Does the H Index Correlate With Academic Rank Among Full-Time Academic Craniofacial Surgeons? Journal of Surgical Education. 2017 Mar - Apr;74(2):222-227.

3. Lopez J, Susarla SM, Swanson EW, Calotta N, Lifchez SD. The Association of the HIndex and Academic Rank Among Full-Time Academic Hand Surgeons Affiliated With Fellowship Programs. The Journal of Hand Surgery. 2015 Jul;40(7):1434-41.

4. Ashfaq A, Kalagara R, Wasif N. H-index and academic rank in general surgery and surgical specialties in the United States. Journal of Surgical Research. 2018 Sep;229:108113.

5. Paik AM, Mady LJ, Villanueva NL, Goljo E, Svider PF, Ciminello F, Eloy JA. Research productivity and gender disparities: a look at academic plastic surgery. J Surg Educ. 2014 Jul-Aug;71(4):593-600.

6. Tomei KL, Nahass MM, Husain Q, Agarwal N, Patel SK, Svider PF, Eloy JA, Liu JK. A gender-based comparison of academic rank and scholarly productivity in academic neurological surgery. J Clin Neurosci. 2014 Jul;21(7):1102-5.

7. Hill EK, Blake RA, Emerson JB, Svider P, Eloy JA, Raker C, Robison K, Stuckey A. Gender Differences in Scholarly Productivity Within Academic Gynecologic Oncology Departments. Obstet Gynecol. 2015 Dec;126(6):1279-84. 
8. Fuller CD, Choi M, Thomas CR Jr. Bibliometric analysis of radiation oncology departmental scholarly publication productivity at domestic residency training institutions. J Am Coll Radiol 2009;6:112-8.

9. Svider PF, Pashkova AA, Choudhry Z, Agarwal N, Kovalerchik O, Baredes S, Liu JK, Eloy JA. Comparison of scholarly impact among surgical specialties: an examination of 2429 academic surgeons. Laryngoscope. 2013 Apr;123(4):884-9.

10. Eloy JA, Svider P, Chandrasekhar SS, Husain Q, Mauro KM, Setzen M, Baredes S. Gender disparities in scholarly productivity within academic otolaryngology departments. Otolaryngol Head Neck Surg. 2013 Feb;148(2):215-22.

11. Shih AF, Sun W, Yick C, Xu S, Fujiwara RJT, Colegio OR. Trends in scholarly productivity of dermatology faculty by academic status and gender. J Am Acad Dermatol. 2019 Jun;80(6):1774-1776.

12. Diamond SJ, Thomas CR Jr, Desai S, Holliday EB, Jagsi R, Schmitt C, Enestvedt BK. Gender Differences in Publication Productivity, Academic Rank, and Career Duration Among U.S. Academic Gastroenterology Faculty. Acad Med. 2016 Aug;91(8):1158-63.

13. Benway BM, Kalidas P, Cabello JM, Bhayani SB. Does citation analysis reveal association between h-index and academic rank in urology? Urology. 2009 Jul;74(1):303.

14. Accreditation council for graduate medical education (ACGME). https://www.acgme.org/. Accessed March 1, 2019.

15. Canadian resident matching service (CaRMS). https://www.carms.ca/. Accessed March 1, 2019. 
16. Kasabwala K, Morton CM, Svider PF, Nahass TA, Eloy JA, Jackson-Rosario I. Factors influencing scholarly impact: does urology fellowship training affect research output? J Surg Educ. 2014 May-Jun;71(3):345-52.

17. Freilich DA, Nguyen HT, Phillips JL. Factors influencing residents' pursuit of urology fellowships. Urology. 2011 Nov;78(5):986-92.

18. Yang G, Zaid UB, Erickson BA, Blaschko SD, Carroll PR, Breyer BN. Urology resident publication output and its relationship to future academic achievement. J Urol. 2011 Feb;185(2):642-6.

19. Reed DA, Enders F, Lindor R, McClees M, Lindor KD. Gender differences in academic productivity and leadership appointments of physicians throughout academic careers. Acad Med. 2011 Jan;86(1):43-7.

20. Yang G, Villalta JD, Weiss DA, Carroll PR, Breyer BN. Gender differences in academic productivity and academic career choice among urology residents. J Urol. 2012 Oct;188(4):1286-90.

21. Mayer EN, Lenherr SM, Hanson HA, Jessop TC, Lowrance WT. Gender Differences in Publication Productivity Among Academic Urologists in the United States. Urology. 2017 May;103:39-46.

22. Pololi LH, Civian JT, Brennan RT, Dottolo AL, Krupat E. Experiencing the culture of academic medicine: gender matters, a national study. J Gen Intern Med. 2013 Feb;28(2):201-7.

23. Chandrasekar T, Goldberg H, Klaassen Z, Wallis CJD, Leong J, Liem S, Teplitsky S, Noorani R, Loeb S. Twitter and academic Urology in the United States and Canada: a 
comprehensive assessment of the Twitterverse in 2019. BJU Int. 2020;125(1):173-181. doi:10.1111/bju.14920

24. Garfield E. Citation indexes for science; a new dimension in documentation through association of ideas. Science. 1955 Jul 15;122(3159):108-11.

25. Hirsch JE. Does the H index have predictive power? Proc Natl Acad Sci U S A. 2007 Dec 4;104(49):19193-8. Epub 2007 Nov 26.

26. Wendl MC. H-index: however ranked, citations need context. Nature. 2007 Sep 27;449(7161):403.

27. Engqvist L, Frommen JG. The h-index and self-citations. Trends Ecol Evol. 2008 May;23(5):250-2.

28. Purvis A. The h index: playing the numbers game. Trends Ecol Evol. 2006 Aug;21(8):422. Epub 2006 Jun 14.

29. Kelly CD, Jennions MD. H-index: age and sex make it unreliable. Nature. 2007 Sep 27;449(7161):403.

30. Kelly CD, Jennions MD. The h index and career assessment by numbers. Trends Ecol Evol. 2006 Apr;21(4):167-70. Epub 2006 Feb 3.

31. Eschelman DJ, Sullivan KL, Parker L, Levin DC. The relationship of clinical and academic productivity in a university hospital radiology department. AJR Am J Roentgenol. 2000 Jan;174(1):27-31. 


\section{FIGURE LEGENDS}

Figure 1: Distribution of $\mathrm{H}$-indices for Academic Urologists in North America

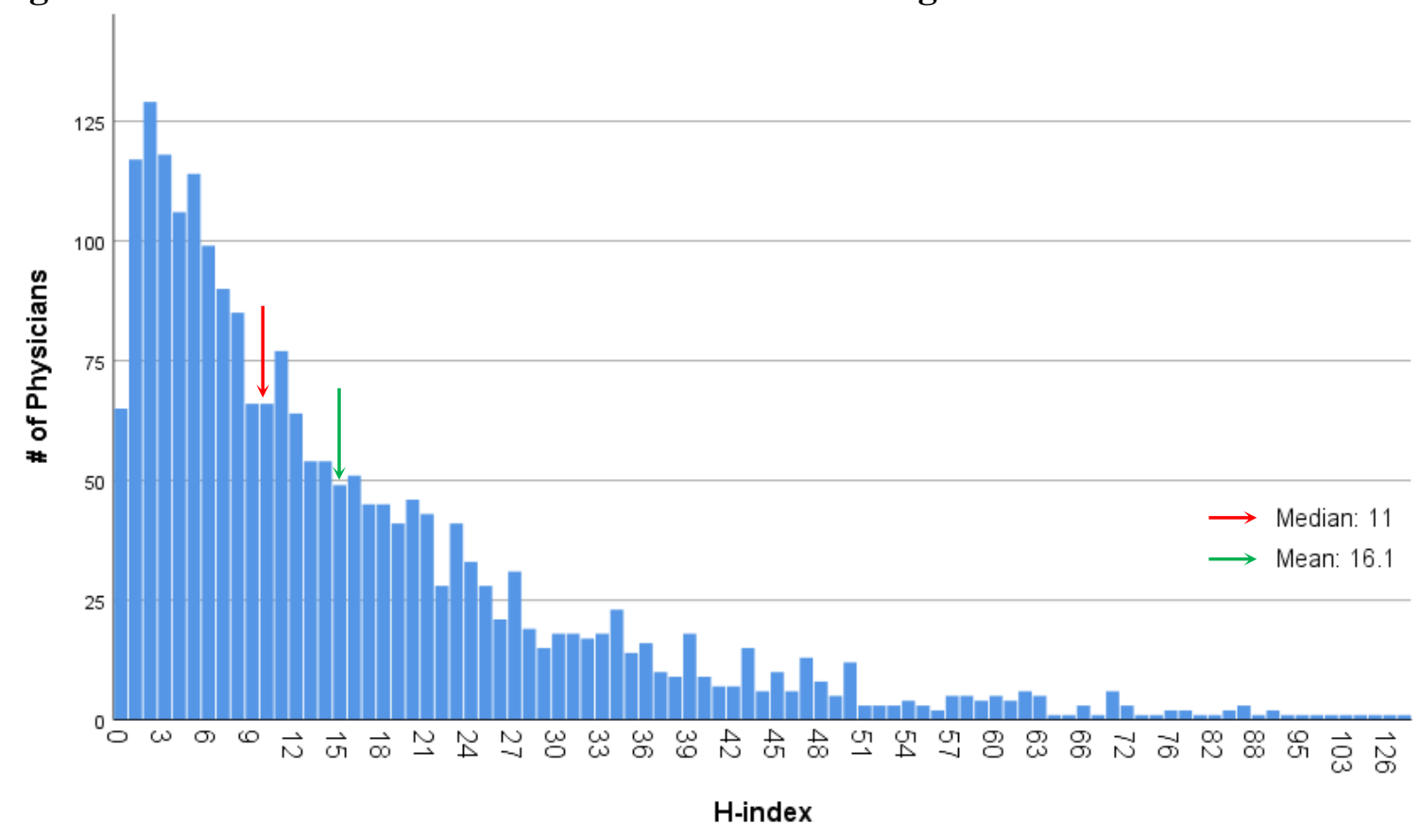


Figure 2: Distribution of number of citations vs. H-index for Academic Urologists in North America

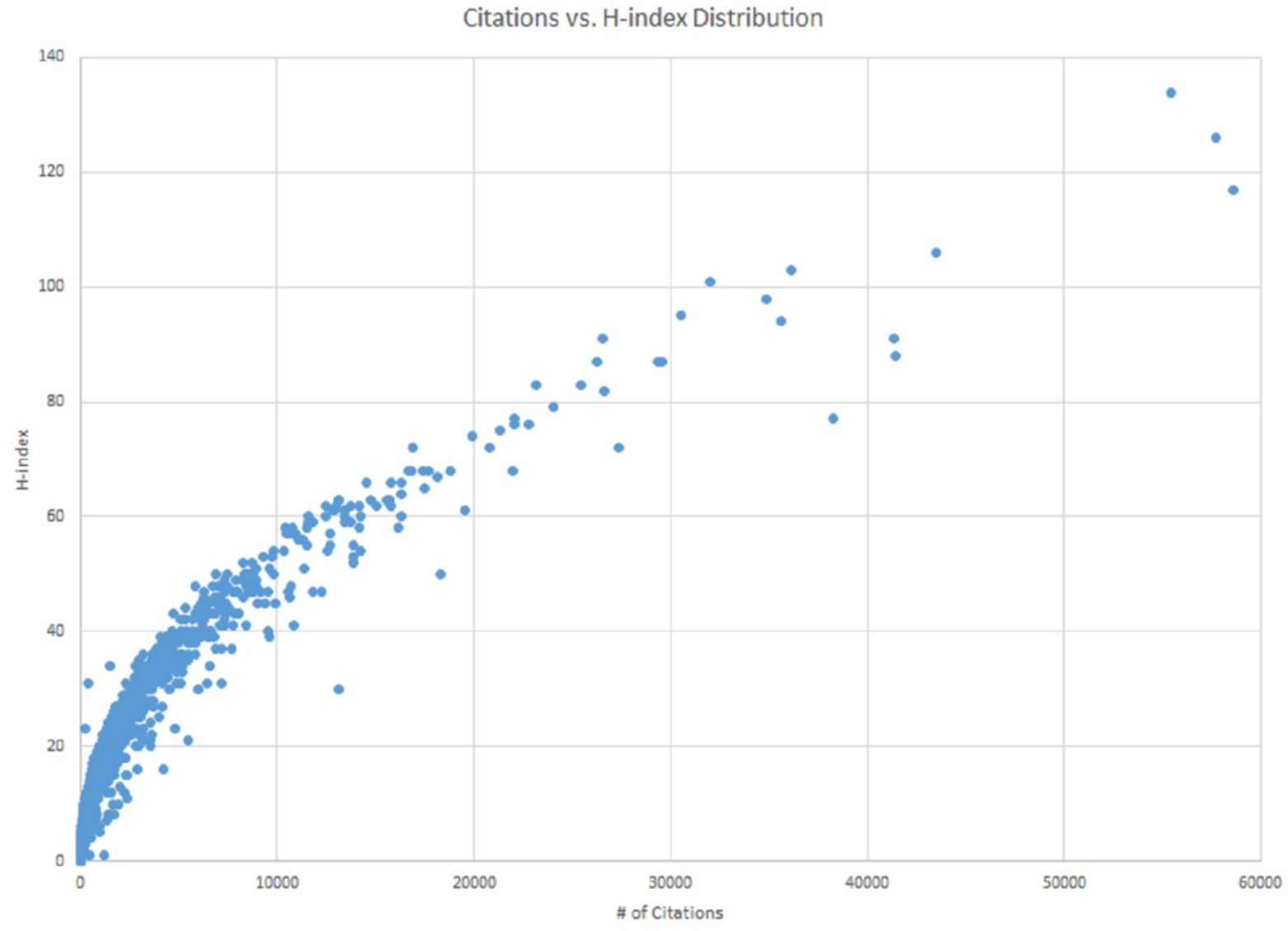


TABLE 1: DEMOGRAPHICS OF ACADEMIC UROLOGISTS IN NORTH AMERICA

\begin{tabular}{|c|c|c|c|c|c|c|}
\hline & $\begin{array}{c}\text { All } \\
\text { Physicians }\end{array}$ & $\begin{array}{c}\text { Clinical } \\
\text { Instructors }\end{array}$ & $\begin{array}{c}\text { Assistant } \\
\text { Professors }\end{array}$ & $\begin{array}{l}\text { Associate } \\
\text { Professors }\end{array}$ & Professors & $\begin{array}{l}p- \\
\text { value }\end{array}$ \\
\hline $\begin{array}{l}\text { Number of Physicians } \\
(\#)\end{array}$ & 2214 & 52 & 841 & 497 & 572 & \\
\hline \multicolumn{6}{|l|}{ AUA Section (n, \%) } & \multirow{9}{*}{$<0.001$} \\
\hline Mid-Atlantic & 257 & $14(5.7 \%)$ & $\begin{array}{c}112 \\
(45.9 \%)\end{array}$ & $58(23.8 \%)$ & $60(24.6 \%)$ & \\
\hline New England & 159 & $5(3.7 \%)$ & $75(56.0 \%)$ & $31(23.1 \%)$ & $23(17.2 \%)$ & \\
\hline New York & 255 & $4(1.9 \%)$ & $\begin{array}{c}117 \\
(55.2 \%)\end{array}$ & $30(14.2 \%)$ & $61(28.8 \%)$ & \\
\hline North Central & 418 & $6(1.7 \%)$ & $\begin{array}{c}140 \\
(40.6 \%)\end{array}$ & $78(22.6 \%)$ & $\begin{array}{c}121 \\
(35.1 \%)\end{array}$ & \\
\hline Northeastern & 253 & $1(0.4 \%)$ & $\begin{array}{c}108 \\
(45.2 \%)\end{array}$ & $60(25.1 \%)$ & $70(29.3 \%)$ & \\
\hline South Central & 187 & $2(1.2 \%)$ & $73(42.7 \%)$ & $45(26.3 \%)$ & $51(29.8 \%)$ & \\
\hline South Eastern & 343 & $7(2.3 \%)$ & $\begin{array}{c}121 \\
(40.1 \%)\end{array}$ & $88(29.1 \%)$ & $86(28.5 \%)$ & \\
\hline Western & 342 & $13(4.1 \%)$ & $95(30.2 \%)$ & $\begin{array}{c}107 \\
(34.0 \%)\end{array}$ & $\begin{array}{c}100 \\
(31.7 \%)\end{array}$ & \\
\hline \multicolumn{6}{|l|}{ Country $(n, \%)$} & \multirow{3}{*}{0.033} \\
\hline United States & 2015 & $48(2.7 \%)$ & $\begin{array}{c}779 \\
(43.9 \%)\end{array}$ & $\begin{array}{c}440 \\
(24.8 \%)\end{array}$ & $\begin{array}{c}508 \\
(28.6 \%)\end{array}$ & \\
\hline Canada & 199 & $4(2.1 \%)$ & $62(33.2 \%)$ & $57(30.5 \%)$ & $64(34.2 \%)$ & \\
\hline \multicolumn{6}{|l|}{ Gender (n, \%) } & \multirow{3}{*}{$<0.001$} \\
\hline Male & 1894 & $40(2.4 \%)$ & $\begin{array}{c}660 \\
(39.4 \%)\end{array}$ & $\begin{array}{c}431 \\
(25.7 \%)\end{array}$ & $\begin{array}{c}545 \\
(32.5 \%)\end{array}$ & \\
\hline Female & 320 & $12(4.2 \%)$ & $\begin{array}{c}181 \\
(63.3 \%) \\
\end{array}$ & $66(23.1 \%)$ & $27(9.4 \%)$ & \\
\hline \multicolumn{6}{|l|}{$\begin{array}{l}\text { Fellowship Trained? } \\
(\mathrm{n}, \%)\end{array}$} & \multirow{3}{*}{0.01} \\
\hline Yes & 1614 & $32(2.2 \%)$ & $\begin{array}{c}628 \\
(42.3 \%)\end{array}$ & $\begin{array}{c}404 \\
(27.2 \%)\end{array}$ & $\begin{array}{c}422 \\
(28.4 \%)\end{array}$ & \\
\hline No & 564 & $19(4.2 \%)$ & $\begin{array}{c}199 \\
(44.2 \%) \\
\end{array}$ & $89(19.8 \%)$ & $\begin{array}{c}143 \\
(31.8 \%) \\
\end{array}$ & \\
\hline \multicolumn{6}{|l|}{$\begin{array}{l}\text { Fellowship Type (n, } \\
\%)\end{array}$} & \multirow{10}{*}{$<0.001$} \\
\hline Urologic Oncology & 487 & $7(1.6 \%)$ & $\begin{array}{c}184 \\
(40.9 \%) \\
\end{array}$ & $\begin{array}{c}113 \\
(25.1 \%)\end{array}$ & $\begin{array}{c}146 \\
(32.4 \%) \\
\end{array}$ & \\
\hline $\begin{array}{l}\text { Minimally Invasive } \\
\text { Surgery/Robotics }\end{array}$ & 98 & $2(2.2 \%)$ & $35(39.3 \%)$ & $24(27.0 \%)$ & $28(31.5 \%)$ & \\
\hline Endourology & 148 & $3(2.2 \%)$ & $63(45.7 \%)$ & $38(27.5 \%)$ & $34(24.6 \%)$ & \\
\hline $\begin{array}{l}\text { Female Pelvic } \\
\text { Medicine }\end{array}$ & 152 & $5(3.6 \%)$ & $63(46.0 \%)$ & $40(29.2 \%)$ & $29(21.2 \%)$ & \\
\hline $\begin{array}{l}\text { Reconstructive } \\
\text { surgery }\end{array}$ & 127 & $3(2.6 \%)$ & $60(51.7 \%)$ & $25(21.6 \%)$ & $28(24.1 \%)$ & \\
\hline Pediatric urology & 337 & $5(1.6 \%)$ & $\begin{array}{c}120 \\
(38.6 \%) \\
\end{array}$ & $\begin{array}{c}101 \\
(32.5 \%) \\
\end{array}$ & 85 (27.3\%) & \\
\hline Infertility/Andrology & 139 & $4(3.1 \%)$ & $63(48.5 \%)$ & $30(23.1 \%)$ & $33(25.4 \%)$ & \\
\hline Transplant & 24 & $0(0 \%)$ & $9(39.1 \%)$ & $6(26.1 \%)$ & $8(34.8 \%)$ & \\
\hline $\begin{array}{c}\text { Multiple } \\
\text { fellowships }\end{array}$ & 70 & $3(4.8 \%)$ & $26(41.9 \%)$ & $19(30.6 \%)$ & $14(22.6 \%)$ & \\
\hline
\end{tabular}


TABLE 2: MEDIAN H-INDEX OF ACADEMIC UROLOGISTS IN NORTH AMERICA STRATIFIED BY ACADEMIC TITLE

\begin{tabular}{|c|c|c|c|c|c|c|}
\hline & $\begin{array}{c}\text { All } \\
\text { Physicians }\end{array}$ & $\begin{array}{c}\text { Clinical } \\
\text { Instructors }\end{array}$ & $\begin{array}{c}\text { Assistant } \\
\text { Professors }\end{array}$ & $\begin{array}{c}\text { Associate } \\
\text { Professors }\end{array}$ & Professors & $\begin{array}{l}\mathrm{p}- \\
\text { value }\end{array}$ \\
\hline All Physicians & 11 & 5 & 6 & 13 & 29 & $<0.001$ \\
\hline \multicolumn{6}{|l|}{ AUA Section } & \multirow{9}{*}{$<0.001$} \\
\hline Mid-Atlantic & 9 & 3 & 6 & 11 & 25 & \\
\hline New England & 11 & 7 & 6 & 14 & 31 & \\
\hline New York & 10 & 12 & 6 & 14 & 26 & \\
\hline North Central & 15 & 3 & 8 & 14 & 33 & \\
\hline Northeastern & 12 & 7 & 6 & 16 & 26 & \\
\hline South Central & 10 & 4.5 & 5 & 10 & 27 & \\
\hline South Eastern & 11 & 8 & 4.5 & 13 & 27 & \\
\hline Western & 14 & 8 & 7 & 14.5 & 28 & \\
\hline \multicolumn{6}{|l|}{ Country } & \multirow{3}{*}{$<0.001$} \\
\hline United States & 11 & 5 & 6 & 13 & 29 & \\
\hline Canada & 17 & 7 & 9 & 17 & 29 & \\
\hline \multicolumn{6}{|l|}{ Gender } & \multirow{3}{*}{$<0.001$} \\
\hline Male & 14 & 5 & 6 & 14 & 29 & \\
\hline Female & 6 & 5 & 5 & 11 & 21 & \\
\hline \multicolumn{6}{|l|}{ Fellowship Trained? } & \multirow{3}{*}{$<0.001$} \\
\hline Yes & 13 & 5.5 & 7 & 14 & 29 & \\
\hline No & 7 & 3.5 & 3 & 7 & 27.5 & \\
\hline \multicolumn{6}{|l|}{ Fellowship Type } & \multirow{10}{*}{$<0.001$} \\
\hline Urologic Oncology & 17 & 8 & 11 & 19 & 37 & \\
\hline $\begin{array}{l}\text { Minimally Invasive } \\
\text { Surgery/Robotics }\end{array}$ & 18 & 4.5 & 11 & 20.5 & 27.5 & \\
\hline Endourology & 12 & 5 & 6 & 18 & 30 & \\
\hline $\begin{array}{l}\text { Female Pelvic } \\
\text { Medicine }\end{array}$ & 10 & 5 & 5 & 12 & 25 & \\
\hline $\begin{array}{l}\text { Reconstructive } \\
\text { surgery }\end{array}$ & 8 & 8 & 4.5 & 9 & 23.5 & \\
\hline Pediatric urology & 11 & 7 & 6 & 12 & 24 & \\
\hline Infertility/Andrology & 11 & 5.5 & 7 & 12.5 & 21 & \\
\hline Transplant & 12 & 2 & 5 & 11.5 & 20.5 & \\
\hline $\begin{array}{r}\text { Multiple } \\
\text { fellowships }\end{array}$ & 11 & 8 & 6 & 14 & 31 & \\
\hline
\end{tabular}


TABLE 3: MULTIVARIATE LOGISTIC REGRESSION ANALYSIS IDENTIFYING PREDICTORS OF H-INDEX GREATER THAN THE MEDIAN (H-Index > 11)

\begin{tabular}{|c|c|c|c|c|}
\hline \multicolumn{2}{|r|}{ Variable } & $\begin{array}{l}\text { Odds Ratio } \\
\text { (OR) }\end{array}$ & $\begin{array}{l}95 \% \text { Confidence } \\
\text { Interval }\end{array}$ & $p$-value \\
\hline \multirow{8}{*}{ AUA Section } & Mid-Atlantic & \multicolumn{3}{|c|}{ REFERENT } \\
\hline & New England & 1.68 & $0.99-2.83$ & 0.05 \\
\hline & New York & 1.40 & $0.86-2.26$ & 0.17 \\
\hline & North Central & 1.75 & $1.15-2.67$ & $<0.01$ \\
\hline & Northeastern & 1.15 & $0.64-2.07$ & 0.64 \\
\hline & South Central & 0.89 & $0.53-1.47$ & 0.64 \\
\hline & South Eastern & 1.11 & $0.72-1.70$ & 0.64 \\
\hline & Western & 1.56 & $1.02-2.40$ & 0.04 \\
\hline \multirow{2}{*}{ Country } & United States & \multicolumn{3}{|c|}{ REFERENT } \\
\hline & Canada & 1.33 & $0.76-2.32$ & 0.32 \\
\hline \multirow{2}{*}{ Gender } & Male & \multicolumn{3}{|c|}{ REFERENT } \\
\hline & Female & 0.34 & $0.24-0.48$ & $<0.01$ \\
\hline \multirow{2}{*}{$\begin{array}{l}\text { Fellowship } \\
\text { Trained }\end{array}$} & No & \multicolumn{3}{|c|}{ REFERENT } \\
\hline & Yes & 3.44 & & $<0.01$ \\
\hline \multirow{4}{*}{ Title } & Clinical Instructor & \multicolumn{3}{|c|}{ REFERENT } \\
\hline & Assistant Professor & 1.02 & $0.48-2.14$ & 0.96 \\
\hline & Associate Professor & 4.59 & $2.17-9.68$ & $<0.01$ \\
\hline & Professor & 30.17 & $13.88-65.54$ & $<0.01$ \\
\hline
\end{tabular}




\section{Take Home Message}

Our study represents the first comprehensive assessment of research productivity metrics amongst academic urologists. These key benchmarks improve our understanding of the landscape for trainees considering academic careers and for practicing physicians gauging their own productivity in relation to peers. 


\section{RESPONSE TO REVIEWERS}

Manuscript Title: EUFOCUS-D-19-00315: "Setting the Standards: Examining Research Productivity amongst Academic Urologists in the United States and Canada in 2019"

First, we would like to thank the reviewers for their input and constructive comments. We hope we have addressed your comments below. Please find a point-by-point review below. All major changes to the original manuscript are highlighted in yellow. Additionally, minor wording changes were incorporated throughout the manuscript for clarification after the addition of new information.

\section{REVIEWER \#1}

1. Comment \#1: In the results 1st para, last sentence- would state the directionality of the findings (e.g. was it yes or no fellowship that was associated with title/position, which gender, etc), otherwise the sentence is not very informative

Response \#1: We thank the reviewer for this comment. The p-values $<0.05$ imply significantly different distributions based on a univariate analysis. We have clarified the findings in the results section with regards to our demographics data to provide some directionality (page 7, paragraph 1). However, directionality is further detailed through the multivariate analysis described in the last paragraph of the results section and Table 3.

"On univariate analysis, a greater proportion of academic urologists in the Canada $(\mathrm{p}=0.033)$, male urologists $(\mathrm{p}<0.001)$, and fellowship-trained urologists $(\mathrm{p}=0.01)$ were likely to be of higher academic title/position."

2. Comment \#2: What was the number of actual publications? Would report this separately from the $\mathrm{h}$ index since the focus is on "research productivity" according to the title- $\mathrm{H}$ index is more about impact whereas raw number of publications still shows productivity (even if some weren't cited)

Response \#2: We would like to thank the reviewer for this comment. The initial database was generated looking at number of citations and h-index only, as that was reported on Scopus, and did not include number of publications. At this point, while we acknowledge this limitation and would have liked to include this data, we have respectfully decided not to go back to capture the data, as the time period of data collection would not coincide with the time period of the initial collection, introducing some variability. However, we feel that citations and h-index, assessed together, carries similar weight. A statement was added to our discussion section acknowledging this limitation (page 13, paragraph 1).

"Our study also did not include data on the raw number of publications for each academic urologist, which may serve as an additional metric for productivity. However, the authors feel that assessing citations and h-index together carries similar weight and provides valuable insight into the urological research landscape." 
3. Comment \#3: Is it possible that some people took on a married name that led to non-capture of earlier publications by the $\mathrm{H}$-index value?

Response \#3: We thank the reviewer for this important question. We acknowledge this as a limitation and have added a statement directly addressing this as a possible source of non-capture (page 13, paragraph 1).

"Additionally, there is the possibility that some urologists, and in particular female urologists, may have taken on a married name, leading to potential non-capture of research output"

4. Comment \#4: Would discuss the positive role of social media in research dissemination and the previous paper showing relationship of social media activity with $\mathrm{H}$-index among academic urologists.

Response \#4: We thank the reviewer for this comment. We have incorporated additional comments in the discussion section to touch on this positive role of social media on research productivity in academic urology and have cited the previous paper (page 12, paragraph 2).

"In further elucidating the academic research productivity landscape within urology, the positive role of social media needs to be discussed. Twitter and other forms of social media engagement continues to rise within urology and allows for rapid and easy dissemination of research ideas and collaboration opportunities. We recently noted in a comprehensive analysis of the Twitterverse amongst academic urologists and programs in North America that there exists an important association between academic productivity and Twitter utilization and metrics (23). Multivariable analysis performed in that study showed that physicians with higher $\mathrm{H}$-indices were more likely to have an individual Twitter account $(\mathrm{p}<0.01)$, however number of citations did not demonstrate the same association. While no causal relationship can be demonstrated, Twitter social media activity may help drive urologic academic productivity and serves as a useful resource and tool to help advance the field."

\section{$\underline{\text { REVIEWER \#2 }}$}

1. Comment \#1: In the discussion, perhaps under limitations I would also add that not all academic tracts require research and publication for promotion. Primary educator academic tracts, for instance, stress education and rely on other metrics for promotion. Not all academic tracts, therefore need to compare to the h-index benchmark as presented. I'm not sure if the authors had access to the is level of data and may confound some of the findings.

Response \#1: We thank the reviewer for this comment. We agree and have added a statement into our discussion section (page 13, last paragraph into page 14). We also acknowledge that the reviewer correctly mentions that we do not have access to that level of data regarding the varying academic tracks. 
"Furthermore, opportunities for career advancement and promotion within academic urology are not always dependent on one's research output. For those in academic tracks with a focus outside of research, such as those stressing education, comparisons to an hindex benchmark may not be as meaningful."

Due to reviewer requests, the manuscript length and number of references exceeds the expected limit. We ask the editors for an allowance, as we feel the above additions from the reviewers are invaluable to the discussion. 
Title: Setting the Standards: Examining Research Productivity amongst Academic Urologists in the United States and Canada in 2019

Running Title: Research Productivity and Academic Urology 2019

Authors: Thenappan Chandrasekar ${ }^{1}$, Timothy M. Han ${ }^{1}$, Lydia Glick $^{1}$, Joon Yau Leong ${ }^{1}$, Seth

Teplitsky $^{1}$, Rodrigo Noorani ${ }^{2}$, Hanan Goldberg ${ }^{3}$, Zachary Klaassen $^{4}$, Christopher JD Wallis ${ }^{5}$,

James R. Mark ${ }^{1}$, Edouard J. Trabulsi ${ }^{1}$, Costas D. Lallas ${ }^{1}$, Leonard G. Gomella ${ }^{1}$

\section{Affiliation:}

1. Department of Urology, Sidney Kimmel Cancer Center, Thomas Jefferson University, Philadelphia, PA

2. Division of Urology, Department of Surgery, University of Toronto, Toronto, ON, Canada 3. Department of Urology, State University of New York Upstate Medical University, Syracuse, NY, USA

4. Division of Urology, Department of Surgery, Augusta University - Medical College of Georgia, Augusta, GA; Georgia Cancer Center, Augusta, GA

5. Department of Urology, Vanderbilt University Medical Center, Nashville, TN, USA

\section{Corresponding Author:}

Thenappan Chandrasekar, MD

Department of Urology, Thomas Jefferson University

1025 Walnut Street, Suite 1100

Philadelphia PA 19107

United States

Phone: 732-742-1025

Fax: 844-351-9508

Email: thenappan.chandrasekar@gmail.com

Funding Source: None

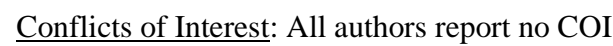

Article Type/Category: Original Article

Summary

Word Count (Manuscript): $2622 \underline{2587}$

Word Count (Abstract): 299

Tables: 3

Figures: 2 
Author Contribution:

1) TC: Conceptualization, Data Curation, Formal Analysis, Writing (Original, Review \&

Editing)

2) TMH, LG, JYL, ST, RN: Formal Analysis, Writing (Review \& Editing)

3) CJDW, ZK, HG, CDL, JRM, EJT, LGG: Resources \& Supervision 


\section{STRUCTURED ABSTRACT}

Background: Research productivity amongst academic urologists is strongly encouraged, but little data is available on productivity metrics within the field.

Objective: To provide the first comprehensive survey of research productivity amongst academic urologists in the United States and Canada.

Methods: Using the Accreditation Council for Graduate Medical Education (ACGME), the Canadian Resident Matching Service (CaRMS) and individual program websites, all active accredited urology faculty were identified. For each individual, we collected data on AUA section, title, gender, fellowship training, Scopus H-index and citations. Comprehensive searches were completed during March-May 2019.

Statistical Analysis: Descriptive statistics for demographic comparisons were performed using analysis of variance (ANOVA) for continuous variables and chi-square test for categorical variables. Multivariable logistic regressions were used to identify predictors of $\mathrm{H}$-index greater than the median.

Results: 2214 academic urology faculty (2015 USA, 199 Canada) were identified. Median and mean H-index for the entire cohort of physicians was 11 and 16.1, respectively. On multivariable analysis, physicians in the North Central and Western Sections (vs. Mid-Atlantic), who were fellowship-trained (vs. no fellowship training), and of higher academic rank (Professor and Associate Professor vs. clinical instructor) were more likely to have $\mathrm{H}$-index values greater than the median. Additionally, female physicians (vs. male) were more likely to have H-index values less than the median.

Conclusion: This study represents the first comprehensive assessment of research productivity metrics amongst academic urologists. These represent key benchmarks for trainees considering 
careers in academics and for practicing physicians gauging their own productivity in relation to their peers.

Patient Summary: In this study, we provide the first comprehensive assessment of research productivity amongst academic urologists in the United States and Canada. Our results help provide key benchmarks for trainees considering careers in academics and for practicing physicians gauging their own productivity in relation to peers. 


\section{INTRODUCTION}

Research productivity has been strongly encouraged within the realm of academic medicine.

Many centers incorporate research productivity into established clinical tracks for academic promotion. For younger physicians who are new to academia, it can prove challenging to assess one's own research contributions and output in the context of their given specialty and practice. Historically and most simply, the number of publications and their citations have served as the cornerstone of assessing research productivity and impact. However, these raw values are limited in characterizing an individual's research presence as higher numbers do not necessarily represent the quality and impact of publications. As a result, various other metrics have arisen to help characterize and quantify research achievement and output. In 2005, Hirsch described and proposed the h-index as a tool to address some of these limitations (1). Defined as the $h$ number of papers with $\geq h$ citations each, the h-index may serve as a useful yardstick in assessing and quantifying scientific achievement (1) by minimizing some of the biases that were seen with using raw number of publications and/or citations as a metric.

The h-index has been used across multiple medical and surgical specialties and has been found to have a strong association with academic productivity and academic standing (2-12). However, there is little data available on these productivity metrics within the field of urology. In 2008, Benway et al. found a strong association between h-index and academic standing by performing a single-day web search of the top 20 academic urology programs (U.S. News and World Report 2008 rankings) (13). Since then, there has been no data further exploring this association and its implications within academic urology. In this study, we aim to provide the first comprehensive survey of research productivity amongst all academic urologists in the United States and Canada in 2019. 


\section{METHODS}

\section{Population and Demographics}

Comprehensive searches were completed for all academic urology programs and physicians during March-May 2019 by using the Accreditation Council for Graduate Medical Education (ACGME) (14), the Canadian Resident Matching Service (CaRMS) (15) and individual program websites. For each of these programs in the United States and Canada, state (if located in the USA), American Urologic Association (AUA) section, and resident class size were recorded. Within these programs, academic urology faculty were identified and catalogued by crossreferencing all available institutional and hospital data. For each individual urologist, gender, academic title, fellowship training and type(s), and AUA section were documented. Academic productivity was characterized by H-index and citations, as per Scopus records (April-May 2019).

\section{$\underline{\text { Statistical Analysis }}$}

Descriptive statistics for demographic comparisons were performed using analysis of variance (ANOVA) for continuous variables and chi-square test for categorical variables. Multivariable logistic regressions were used to identify predictors of $\mathrm{H}$-index greater than the median $(>11)$. All statistical tests were two-tailed and a p-value of $<0.05$ was considered statistically significant. Analyses were completed using SPSS®, version 23.0. 


\section{RESULTS}

$\underline{\text { Demographics }}$

Through comprehensive search using the ACGME, CaRMS, and individual academic urology program data, 2214 academic urology faculty (2015 USA, 199 Canada) were identified.

Demographics of academic urologists, stratified by academic position, are summarized in Table

1. The majority of academic urologists were Assistant Professors (38.0\%); the remaining were primarily Associate Professors (22.4\%) or full Professors (25.8\%), with a small proportion being Clinical Instructors (2.3\%). 252 (11.4\%) of the academic urologists had unlisted academic positions. On univariate analysis, there existed a significant difference in distribution of academic title/position across AUA section ( $p<0.001)$ and fellowship type ( $p<0.001)$, country ( $p=0.033)$, gender ( $p<0.001)$, fellowship training ( $p=0.01)$ and fellowship type $(p<0.001)$ were all significantly associated with a physician's academic title and position. Additionally, a greater proportion of academic urologists in the USA ( $p=0.033)$, male urologists $(p<0.001)$, and

\section{fellowship-trained urologists ( $\mathrm{p}=0.01$ ) were likely to be of higher academic title/position.}

\section{$\underline{\text { H-index distribution }}$}

H-index was catalogued for each physician when available; for the entire cohort, the calculated median $\mathrm{H}$-index was 11 and the mean was 16.1. Figure 1 depicts the distribution of $\mathrm{H}$-indices for academic urologists in North America. Figure 2 shows the distribution of H-indices when matched to each individual urologist's number of citations, demonstrating a strong correlation between number of citations and $\mathrm{H}$-index.

$\underline{\text { Univariate analysis of median } \mathrm{H} \text {-index stratified by academic title }}$

Table 2 summarizes median $\mathrm{H}$-indices as stratified by academic title. First, there is a significant step-wise increase in the median $\mathrm{H}$-index with academic promotion, from 5 for Clinical 
Instructors to 29 for Professors $(\mathrm{p}<0.001)$. Median H-indices tended to be higher in the North Central and New England AUA Sections and lower in the South Central and Southeastern AUA sections $(\mathrm{p}<0.001)$. Higher median H-indices were also identified among Canadian academic urologists $(\mathrm{p}<0.001)$, male academic urologists $(\mathrm{p}<0.001)$, and physicians with fellowship training $(\mathrm{p}<0.001)$, specifically in Urologic Oncology, MIS/Robotics or multiple fellowships. Predictors of higher H-index and academic productivity

Multivariate logistic regression analysis was performed to identify predictors of higher academic productivity, defined as an $\mathrm{H}$-index greater than the median $(\mathrm{H}$-index $>11)$. When compared to the Mid-Atlantic AUA Section, the North Central (OR 1.75, 95CI 1.15-2.67, p<0.01) and Western (OR 1.56, 95CI 1.02-2.40, $\mathrm{p}=0.04)$ Sections were more likely to have H-index values greater than the median. Physicians who were fellowship-trained (vs. no fellowship training: OR 3.44, 95CI 2.56-4.63, $\mathrm{p}<0.01$ ) and physicians of higher academic rank (vs. clinical instructor: Associate Professor [OR 4.59, 95CI 2.17-9.68, p<0.01], Professor [OR 30.17, 95CI 13.88-65.54, $\mathrm{p}<0.01]$ ) were also more likely to have $\mathrm{H}$-index values $>11$. Female physicians (vs. male: OR $0.34,95 \mathrm{CI} 2.56-4.63, \mathrm{p}<0.01)$ were more likely to have $\mathrm{H}$-index values less than the median. There was no statistically significant association between country and H-index. 
9| Page 


\section{DISCUSSION:}

Through this assessment of all academic urology programs in the US and Canada, we provide the first comprehensive evaluation of academic productivity within academic Urology. In contrast to the study of Benway et al. (13), which was limited to the top 20 programs (by U.S. News and World Report 2008 rankings), we examined all academic urology programs with associated residency programs, thereby providing a comprehensive assessment of academic urology programs.

Benway et al. demonstrated a close association between H-index and academic position (13). In our assessment of all academic urology programs and their 2214 academic urology faculty (2015 USA, 199 Canada), we validated their findings. On multivariable analysis, physicians of higher academic rank were more likely to have higher H-indices; however, this only applied to Professors and Associate Professors. While our dataset did not capture age, academic title may serve as a surrogate for physician age. However, it should be noted that the title of Assistant Professor was the most common academic position in the entire cohort, representing $38.0 \%$ (841/2214) of all physicians. Within academic medicine, it is not uncommon for Assistant Professors to include both new faculty with great interest in academic productivity and older faculty who were primarily clinically focused and did not pursue promotion. Hence, this group likely represented a much wider age range, and may account for why the median $\mathrm{H}$-index did not seem to significantly rise until Associate Professor status was reached.

Beyond academic title, fellowship training appears to be an important predictor of academic output. Fellowship trained physicians were 3.44 times more likely to have an H-index greater than the median $(\mathrm{H}$-index $>11)$. Interestingly, our findings of the impact of fellowship training on academic productivity conflicts with prior studies. In 2014, Kasabwala et al. looked at 851 
faculty members from 101 academic urology departments and found no statistical difference in h-index between fellowship-trained and non-fellowship-trained academic urologists (16). Certain factors may contribute to these differences. First, as seen in Table 1, 21.9\% (232/1058) of all Associate Professors and Professors are not fellowship trained. Historically, clinical fellowship training was not as predominant as it is now, nor was it considered a pre-requisite for academic advancement. Hence, many senior academic urologists did not have formal fellowship training yet still advanced academically. Therefore, incorporation of these individuals may skew the results in favor of non-fellowship trained physicians, particularly in older studies. Our study, done more than 5 years later, may be better reflective of clinically active non-retired physicians. It is also possible that with a larger sample size of physicians (2214 vs. 851$)$ and programs (156 vs. 101), our data represented a better cross-section of the field. Regardless, this relationship between fellowship-training and $\mathrm{H}$-index warrants further exploration, specifically as it may reflect and affect trainees' decision to enter the academic sector after residency. In 2011, Freilich et al. conducted a survey of residents revealing that the "most important" factors influencing the pursuit of urology fellowship were intellectual appeal (82\%), mentorship opportunities (79\%), the desire for an additional point of view for surgical training (58\%), and the desire to pursue and a career in academia (52\%) (17). Additionally, the survey revealed that urologists who publish (first author or co-author) while in residency were roughly 6 times more likely to pursue fellowship training (17). As a result, it would appear that those individuals who currently choose to pursue fellowship training are self-selected, as those who are likely to pursue academic medicine work towards publishing during training and in subsequent practice. Yang et al. demonstrated that increased research publication output during residency correlated with increasing dedicated research time and was associated with the pursuit of fellowship training and 
a career in academia (18). As residency training continues to be shortened, sometimes at the expense of dedicated research, future prospective studies are needed to evaluate the impact of reduced dedicated research time on academic productivity during residency, and the decision to pursue fellowship training and academic careers, especially as academic careers increasingly emphasize productivity metrics.

Lastly, in our study, we did note that female gender was independently associated with less than median $\mathrm{H}$-index values $(\mathrm{H}-\mathrm{index} \leq 11)$. This contributes to the growing body of literature within medicine exploring potential gender disparities in the academic sector $(5-7,10-12,19-22)$. In a study from 2007 at Mayo Clinic, Reed et al. discovered that while women held fewer leadership roles throughout their careers $(\mathrm{p}<0.001)$, their publication rates increased and actually exceeded those of men in the latter stages of their careers (19). This unique productivity curve was again demonstrated among otolaryngology departments; while female physicians had lower research output earlier in their careers, their research output equaled or exceeded research productivity of men at more senior levels (10). Additionally, research output was found to be equal between men and women at higher academic ranks in the fields of gynecologic oncology (7), gastroenterology (12), dermatology (11), and neurologic surgery (6). Within urology, the existing literature suggests similar trends and gender disparities. Yang et al. showed that despite there being a higher proportion of women than men who pursued fellowship training and ultimately decided upon an academic career, female urology residents produced fewer total publications than men (p $=0.01)$, with fewer as first author $(\mathrm{p}=0.03)$ than men $(20)$. Furthermore, among trainees who pursued academia, a higher proportion of men $(\mathrm{p}=0.01)$ obtained Associate vs Assistant Professor rank (20). Mayer et al. showed that while male urologists had higher median H-indices than women overall $(\mathrm{p}<0.05)$ and higher academic ranks $(\mathrm{p}<0.05)$, there was no difference 
between genders in research productivity by successive rank after controlling for career duration (m-quotient) (21). It is clear that within the field of academic urology and medicine as a whole, implicit biases may exist favoring male physicians. In a study by Pololi et al. looking at a stratified random sample of 4578 full-time faculty (53\% female respondents), female faculty reported a lower sense of belonging and relationships within the workplace $(\mathrm{p}<0.01)$, lower selfefficacy for career advancement ( $\mathrm{p}<0.001)$, lower perceived gender equity $(\mathrm{p}<0.001)$, and lower belief that their respective institutions were making changes to address diversity goals ( $\mathrm{p}<$ 0.001) (22). Therefore, although women continue to represent a growing proportion of academic medicine, within and beyond urology, more efforts should be put forth to further elucidate these gender disparities and ultimately to address them effectively.

In further elucidating the academic research productivity landscape within urology, the positive role of social media needs to be discussed. Twitter and other forms of social media engagement $\underline{\text { continues to rise within urology and allows for rapid and easy dissemination of research ideas }}$ and collaboration opportunities. Chandrasekar et al.We recently noted in a comprehensive analysis of the Twitterverse amongst academic urologists and programs in North America that there exists an important association between academic productivity and Twitter utilization and metrics (23). Multivariable analysis performed in that study showed that physicians with higher $\underline{\text { H-indices were more likely to have an individual Twitter account }(\mathrm{p}<0.01) \text {, however number of }}$ citations did not demonstrate the same association. While no causal relationship can be demonstrated, Twitter social media activity may help drive urologic academic productivity and serves as a useful resource and tool to help advance the field.

This study is not devoid of limitations. First, as the capture of program and physician metrics and Scopus academic metrics were manual, there is the potential for incomplete capture. In Scopus, 
many physicians had multiple listings due to prior academic affiliations, which were collated when identifiable. Additionally, there is the possibility that some urologists, and in particular $\underline{\text { female urologists, } \text { may have taken on a married name, leading to potential non-capture of }}$ research output mnder the other name. Ultimately, however, as an extensive effort was made to thoroughly perform these web searches using multiple key words, name combinations, and as most physicians were identified on Scopus, the authors are confident that the capture rate was quite high. Second, the use of the h-index as a valid tool has been criticized in published data (1, 243-30-29) and must be weighed against the strength of the associations and conclusions drawn in this study. Our study also did not include data on the raw number of publications for each Formatted: Highlight $\underline{\text { academic urologist, which may serve as an additional metric for productivity. However, the }}$ $\underline{\text { authors feel that assessing citations and h-index together carries similar weight and provides }}$ valuable insight into the urological research landscape. Finally, it is challenging to measure an academic urologist's contributions to a department merely using h-index or academic productivity, as his/her role within the department is complex, consisting of various metrics including research output, teaching, surgical skill, clinical acumen, and other responsibilities. In a study performed within a radiology department in 2000, Eschelman et al. found that faculty members with higher levels of clinical productivity (measured by the number of total professional relative value units generated) showed significantly lower levels of academic productivity (determined by number of published articles, abstracts, and presentations) (30 $\underline{31}$ ). Therefore, it is difficult to distill an academic urologists' contributions down to one metric focused specifically on research output (h-index). Furthermore, opportunities for career $\underline{\text { advancement and promotion within academic urology are not always dependent on one's }}$ research output. For those in academic tracks with a focus outside of research, such as those 
stressing education, comparisons to an h-index benchmark may not be as meaningful

Furthermore, opportunities for career advancement and promotion within academic urology are

Formatted: Highlight

not always dependent on one's research output. For those in academic tracks with focuses

outside of research, such as those stressing education, comparing to an $h$ index benchmark may

not be as useful. 


\section{CONCLUSION}

There is a paucity of literature and current data for trainees and staff to gauge their own productivity as they enter clinical practice following urology residency. This study represents the first comprehensive assessment of research productivity metrics amongst academic urologists.

This data are not meant to serve as a criterion in assessing academic urologists interested in career advancement and promotion, but rather to help provide key benchmarks for trainees considering careers in academics and for practicing physicians gauging their own productivity in relation to their peers. The reality is that most academic urologists have $\mathrm{H}$-indices closer to 10 or lower (mean 16.1, median 11), which can be reassuring for younger urologists finishing up training. However, the climb from assistant to associate professorship and beyond becomes much steeper, and these benchmarks can help create a better understanding of that landscape. 


\section{REFERENCES / BIBLIOGRAPHY}

1. Hirsch JE. An index to quantify an individual's scientific research output. Proceedings of the National Academy of Sciences of the United States of America. 2005 Nov $15 ; 102(46): 16569-72$.

2. Susarla SM, Rada EM, Lopez J, Swanson EW, Miller D, Redett RJ, Kumar AR. Does the H Index Correlate With Academic Rank Among Full-Time Academic Craniofacial Surgeons? Journal of Surgical Education. 2017 Mar - Apr;74(2):222-227.

3. Lopez J, Susarla SM, Swanson EW, Calotta N, Lifchez SD. The Association of the HIndex and Academic Rank Among Full-Time Academic Hand Surgeons Affiliated With Fellowship Programs. The Journal of Hand Surgery. 2015 Jul;40(7):1434-41.

4. Ashfaq A, Kalagara R, Wasif N. H-index and academic rank in general surgery and surgical specialties in the United States. Journal of Surgical Research. 2018 Sep;229:108113.

5. Paik AM, Mady LJ, Villanueva NL, Goljo E, Svider PF, Ciminello F, Eloy JA. Research productivity and gender disparities: a look at academic plastic surgery. J Surg Educ. 2014 Jul-Aug;71(4):593-600.

6. Tomei KL, Nahass MM, Husain Q, Agarwal N, Patel SK, Svider PF, Eloy JA, Liu JK. A gender-based comparison of academic rank and scholarly productivity in academic neurological surgery. J Clin Neurosci. 2014 Jul;21(7):1102-5.

7. Hill EK, Blake RA, Emerson JB, Svider P, Eloy JA, Raker C, Robison K, Stuckey A. Gender Differences in Scholarly Productivity Within Academic Gynecologic Oncology Departments. Obstet Gynecol. 2015 Dec;126(6):1279-84. 
8. Fuller CD, Choi M, Thomas CR Jr. Bibliometric analysis of radiation oncology departmental scholarly publication productivity at domestic residency training institutions. J Am Coll Radiol 2009;6:112-8.

9. Svider PF, Pashkova AA, Choudhry Z, Agarwal N, Kovalerchik O, Baredes S, Liu JK, Eloy JA. Comparison of scholarly impact among surgical specialties: an examination of 2429 academic surgeons. Laryngoscope. 2013 Apr;123(4):884-9.

10. Eloy JA, Svider P, Chandrasekhar SS, Husain Q, Mauro KM, Setzen M, Baredes S.

Gender disparities in scholarly productivity within academic otolaryngology departments. Otolaryngol Head Neck Surg. 2013 Feb;148(2):215-22.

11. Shih AF, Sun W, Yick C, Xu S, Fujiwara RJT, Colegio OR. Trends in scholarly productivity of dermatology faculty by academic status and gender. J Am Acad Dermatol. 2019 Jun;80(6):1774-1776.

12. Diamond SJ, Thomas CR Jr, Desai S, Holliday EB, Jagsi R, Schmitt C, Enestvedt BK. Gender Differences in Publication Productivity, Academic Rank, and Career Duration Among U.S. Academic Gastroenterology Faculty. Acad Med. 2016 Aug;91(8):1158-63.

13. Benway BM, Kalidas P, Cabello JM, Bhayani SB. Does citation analysis reveal association between h-index and academic rank in urology? Urology. 2009 Jul;74(1):303.

14. Accreditation council for graduate medical education (ACGME). https://www.acgme.org/. Accessed March 1, 2019.

15. Canadian resident matching service (CaRMS). https://www.carms.ca/. Accessed March $1,2019$. 
16. Kasabwala K, Morton CM, Svider PF, Nahass TA, Eloy JA, Jackson-Rosario I. Factors influencing scholarly impact: does urology fellowship training affect research output? J Surg Educ. 2014 May-Jun;71(3):345-52.

17. Freilich DA, Nguyen HT, Phillips JL. Factors influencing residents' pursuit of urology fellowships. Urology. 2011 Nov;78(5):986-92.

18. Yang G, Zaid UB, Erickson BA, Blaschko SD, Carroll PR, Breyer BN. Urology resident publication output and its relationship to future academic achievement. J Urol. 2011 Feb;185(2):642-6.

19. Reed DA, Enders F, Lindor R, McClees M, Lindor KD. Gender differences in academic productivity and leadership appointments of physicians throughout academic careers. Acad Med. 2011 Jan;86(1):43-7.

20. Yang G, Villalta JD, Weiss DA, Carroll PR, Breyer BN. Gender differences in academic productivity and academic career choice among urology residents. J Urol. 2012

Oct;188(4):1286-90.

21. Mayer EN, Lenherr SM, Hanson HA, Jessop TC, Lowrance WT. Gender Differences in Publication Productivity Among Academic Urologists in the United States. Urology. 2017 May;103:39-46.

22. Pololi LH, Civian JT, Brennan RT, Dottolo AL, Krupat E. Experiencing the culture of academic medicine: gender matters, a national study. J Gen Intern Med. 2013 Feb;28(2):201-7. 


\section{comprehensive assessment of the Twitterverse in 2019. BJU Int. 2020;125(1):173-181.}

doi:10.1111/bju.14920

Formatted: Highlight

23.24. Garfield E. Citation indexes for science; a new dimension in documentation through association of ideas. Science. 1955 Jul 15;122(3159):108-11.

24.25. Hirsch JE. Does the H index have predictive power? Proc Natl Acad Sci U S A. 2007 Dec 4;104(49):19193-8. Epub 2007 Nov 26.

25.26. Wendl MC. H-index: however ranked, citations need context. Nature. 2007 Sep $27 ; 449(7161): 403$

26.27. Engqvist L, Frommen JG. The h-index and self-citations. Trends Ecol Evol. 2008 May;23(5):250-2.

27.28. Purvis A. The h index: playing the numbers game. Trends Ecol Evol. 2006 Aug;21(8):422. Epub 2006 Jun 14.

28.29. Kelly CD, Jennions MD. H-index: age and sex make it unreliable. Nature. 2007 Sep 27;449(7161):403.

29.30. Kelly CD, Jennions MD. The $\mathrm{h}$ index and career assessment by numbers. Trends Ecol Evol. 2006 Apr;21(4):167-70. Epub 2006 Feb 3.

30.31. Eschelman DJ, Sullivan KL, Parker L, Levin DC. The relationship of clinical and academic productivity in a university hospital radiology department. AJR Am J

Roentgenol. 2000 Jan;174(1):27-31. 


\section{FIGURE LEGENDS}

Figure 1: Distribution of H-indices for Academic Urologists in North America

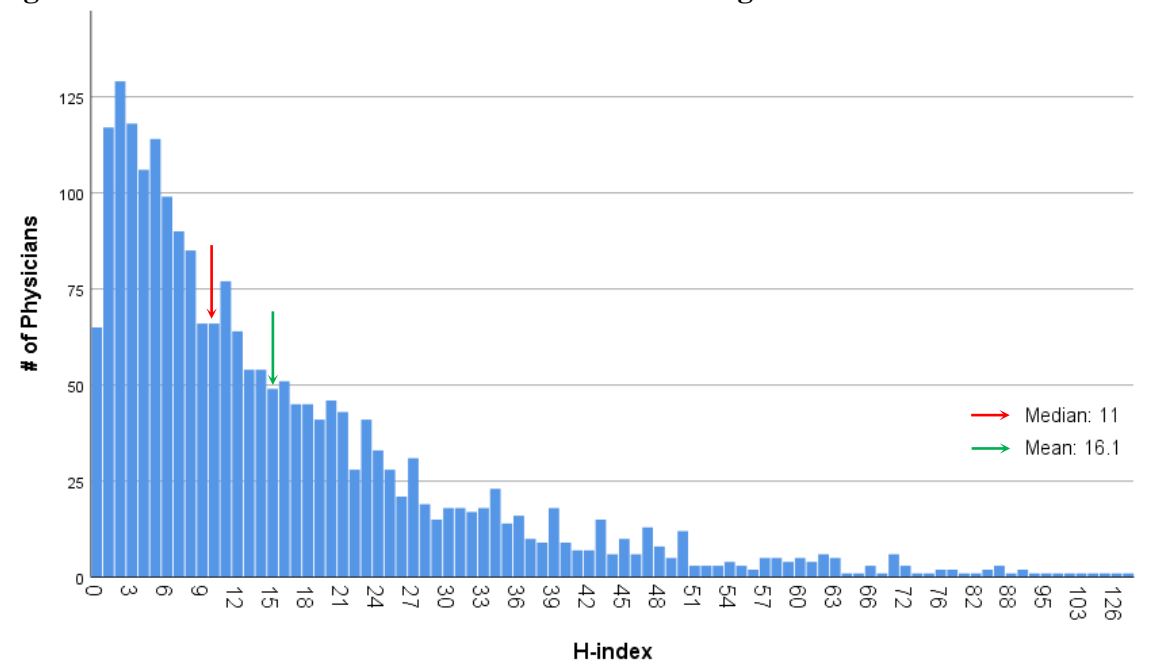


Figure 2: Distribution of number of citations vs. H-index for Academic Urologists in North America

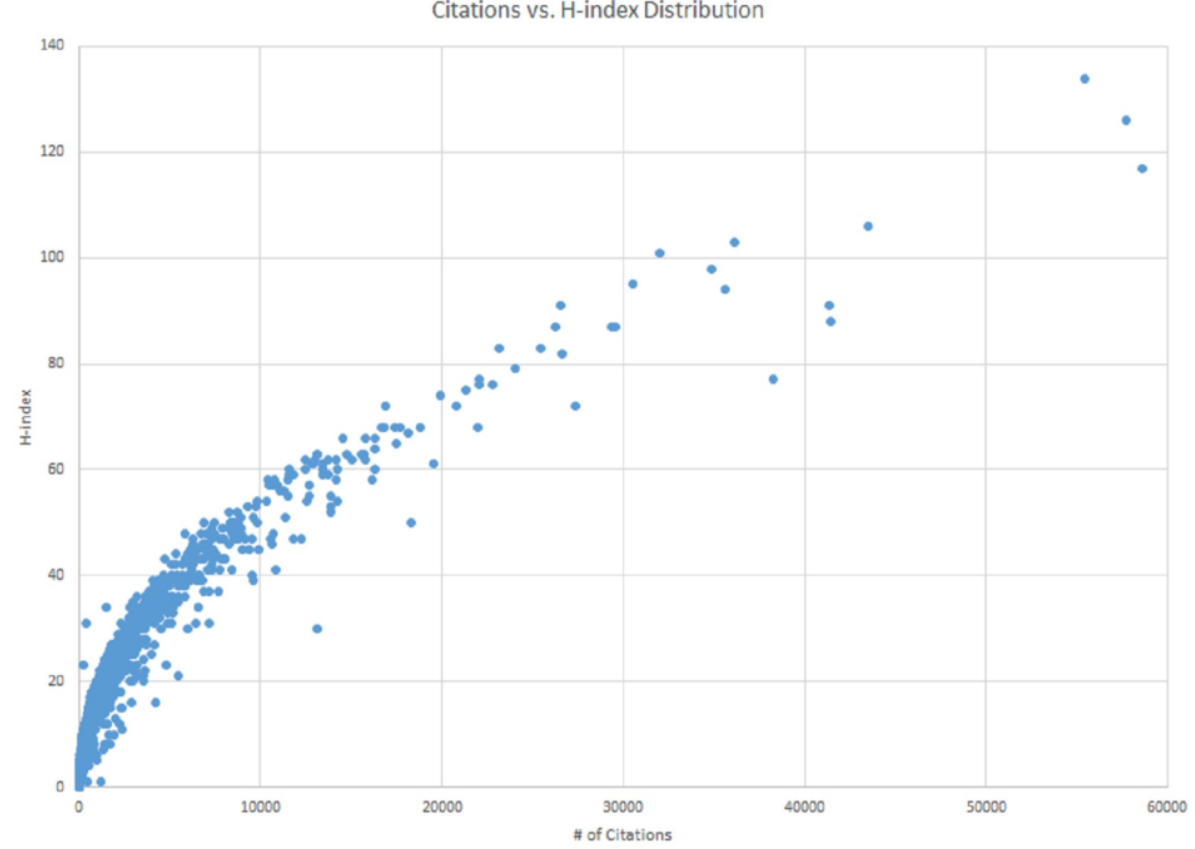


TABLE 1: DEMOGRAPHICS OF ACADEMIC UROLOGISTS IN NORTH AMERICA

\begin{tabular}{|c|c|c|c|c|c|c|}
\hline & $\begin{array}{c}\text { All } \\
\text { Physicians }\end{array}$ & $\begin{array}{c}\text { Clinical } \\
\text { Instructors }\end{array}$ & $\begin{array}{c}\text { Assistant } \\
\text { Professors }\end{array}$ & $\begin{array}{l}\text { Associate } \\
\text { Professors }\end{array}$ & Professors & $\begin{array}{l}\text { p- } \\
\text { value }\end{array}$ \\
\hline $\begin{array}{l}\text { Number of Physicians } \\
(\#)\end{array}$ & 2214 & 52 & 841 & 497 & 572 & \\
\hline \multicolumn{6}{|l|}{ AUA Section $(n, \%)$} & \multirow{9}{*}{$<0.001$} \\
\hline Mid-Atlantic & 257 & $14(5.7 \%)$ & $\begin{array}{c}112 \\
(45.9 \%)\end{array}$ & $58(23.8 \%)$ & $60(24.6 \%)$ & \\
\hline New England & 159 & $5(3.7 \%)$ & $75(56.0 \%)$ & $31(23.1 \%)$ & $23(17.2 \%)$ & \\
\hline New York & 255 & $4(1.9 \%)$ & $\begin{array}{c}117 \\
(55.2 \%) \\
\end{array}$ & $30(14.2 \%)$ & $61(28.8 \%)$ & \\
\hline North Central & 418 & $6(1.7 \%)$ & $\begin{array}{c}140 \\
(40.6 \%)\end{array}$ & $78(22.6 \%)$ & $\begin{array}{c}121 \\
(35.1 \%) \\
\end{array}$ & \\
\hline Northeastern & 253 & $1(0.4 \%)$ & $\begin{array}{c}108 \\
(45.2 \%)\end{array}$ & $60(25.1 \%)$ & $70(29.3 \%)$ & \\
\hline South Central & 187 & $2(1.2 \%)$ & $73(42.7 \%)$ & $45(26.3 \%)$ & $51(29.8 \%)$ & \\
\hline South Eastern & 343 & $7(2.3 \%)$ & $\begin{array}{c}121 \\
(40.1 \%)\end{array}$ & $88(29.1 \%)$ & $86(28.5 \%)$ & \\
\hline Western & 342 & $13(4.1 \%)$ & $95(30.2 \%)$ & $\begin{array}{c}107 \\
(34.0 \%) \\
\end{array}$ & $\begin{array}{c}100 \\
(31.7 \%) \\
\end{array}$ & \\
\hline Country $(n, \%)$ & & & & & & \multirow{3}{*}{0.033} \\
\hline United States & 2015 & $48(2.7 \%)$ & $\begin{array}{c}779 \\
(43.9 \%)\end{array}$ & $\begin{array}{c}440 \\
(24.8 \%)\end{array}$ & $\begin{array}{c}508 \\
(28.6 \%)\end{array}$ & \\
\hline Canada & 199 & $4(2.1 \%)$ & $62(33.2 \%)$ & $57(30.5 \%)$ & $64(34.2 \%)$ & \\
\hline \multicolumn{6}{|l|}{ Gender (n, \%) } & \multirow{3}{*}{$<0.001$} \\
\hline Male & 1894 & $40(2.4 \%)$ & $\begin{array}{c}660 \\
(39.4 \%)\end{array}$ & $\begin{array}{c}431 \\
(25.7 \%)\end{array}$ & $\begin{array}{c}545 \\
(32.5 \%)\end{array}$ & \\
\hline Female & 320 & $12(4.2 \%)$ & $\begin{array}{c}181 \\
(63.3 \%)\end{array}$ & $66(23.1 \%)$ & $27(9.4 \%)$ & \\
\hline \multicolumn{6}{|l|}{$\begin{array}{l}\text { Fellowship Trained? } \\
(\mathrm{n}, \%)\end{array}$} & \multirow{3}{*}{0.01} \\
\hline Yes & 1614 & $32(2.2 \%)$ & $\begin{array}{c}628 \\
(42.3 \%)\end{array}$ & $\begin{array}{c}404 \\
(27.2 \%)\end{array}$ & $\begin{array}{c}422 \\
(28.4 \%)\end{array}$ & \\
\hline No & 564 & $19(4.2 \%)$ & $\begin{array}{c}199 \\
(44.2 \%)\end{array}$ & $89(19.8 \%)$ & $\begin{array}{c}143 \\
(31.8 \%)\end{array}$ & \\
\hline \multicolumn{6}{|l|}{$\begin{array}{l}\text { Fellowship Type (n, } \\
\%)\end{array}$} & \multirow{8}{*}{$<0.001$} \\
\hline & 487 & $7(1.6 \%)$ & 184 & 113 & 146 & \\
\hline Urologic Oncology & & & $(40.9 \%)$ & $(25.1 \%)$ & $(32.4 \%)$ & \\
\hline $\begin{array}{l}\text { Minimally Invasive } \\
\text { Surgery/Robotics }\end{array}$ & 98 & $2(2.2 \%)$ & $35(39.3 \%)$ & $24(27.0 \%)$ & $28(31.5 \%)$ & \\
\hline Endourology & 148 & $3(2.2 \%)$ & $63(45.7 \%)$ & $38(27.5 \%)$ & $34(24.6 \%)$ & \\
\hline Female Pelvic & 152 & $5(3.6 \%)$ & $63(46.0 \%)$ & $40(29.2 \%)$ & $29(21.2 \%)$ & \\
\hline Medicine & & & & & & \\
\hline \multirow{2}{*}{$\begin{array}{l}\text { Reconstructive } \\
\text { surgery }\end{array}$} & 127 & $3(2.6 \%)$ & $60(51.7 \%)$ & $25(21.6 \%)$ & $28(24.1 \%)$ & \\
\hline & & & & & & \\
\hline & 337 & $5(1.6 \%)$ & 120 & 101 & $85(27.3 \%)$ & \\
\hline Pediatric urology & & & $(38.6 \%)$ & $(32.5 \%)$ & & \\
\hline Infertility/Andrology & 139 & $4(3.1 \%)$ & $63(48.5 \%)$ & $30(23.1 \%)$ & $33(25.4 \%)$ & \\
\hline Transplant & 24 & $0(0 \%)$ & $9(39.1 \%)$ & $6(26.1 \%)$ & $8(34.8 \%)$ & \\
\hline $\begin{array}{r}\text { Multiple } \\
\text { fellowships }\end{array}$ & 70 & $3(4.8 \%)$ & $26(41.9 \%)$ & $19(30.6 \%)$ & $14(22.6 \%)$ & \\
\hline
\end{tabular}

\begin{tabular}{|c|c|}
\hline Formatted & $\ldots$ \\
\hline \multicolumn{2}{|l|}{ Formatted } \\
\hline \multicolumn{2}{|l|}{ Formatted } \\
\hline \multicolumn{2}{|l|}{ Formatted } \\
\hline \multicolumn{2}{|l|}{ Formatted } \\
\hline \multicolumn{2}{|l|}{ Formatted } \\
\hline \multicolumn{2}{|l|}{ Formatted } \\
\hline \multicolumn{2}{|l|}{ Formatted } \\
\hline \multicolumn{2}{|l|}{ Formatted } \\
\hline \multicolumn{2}{|l|}{ Formatted } \\
\hline \multicolumn{2}{|l|}{ Formatted } \\
\hline \multicolumn{2}{|l|}{ Formatted } \\
\hline \multicolumn{2}{|l|}{ Formatted } \\
\hline \multicolumn{2}{|l|}{ Formatted } \\
\hline \multicolumn{2}{|l|}{ Formatted } \\
\hline \multicolumn{2}{|l|}{ Formatted } \\
\hline \multicolumn{2}{|l|}{ Formatted } \\
\hline \multicolumn{2}{|l|}{ Formatted } \\
\hline \multicolumn{2}{|l|}{ Formatted } \\
\hline \multicolumn{2}{|l|}{ Formatted } \\
\hline \multicolumn{2}{|l|}{ Formatted } \\
\hline \multicolumn{2}{|l|}{ Formatted } \\
\hline \multicolumn{2}{|l|}{ Formatted } \\
\hline \multicolumn{2}{|l|}{ Formatted } \\
\hline Formatted & \\
\hline Formatted & \\
\hline Formatted & \\
\hline Formatted & \\
\hline Formatted & \\
\hline Formatted & \\
\hline Formatted & \\
\hline Formatted & \\
\hline Formatted & \\
\hline Formatted & \\
\hline Formatted & \\
\hline Formatted & \\
\hline Formatted & \\
\hline Formatted & \\
\hline Formatted & \\
\hline Formatted & \\
\hline Formatted & \\
\hline Formatted & 1 \\
\hline Formatted & \\
\hline Formatted & \\
\hline Formatted & a. \\
\hline Formatted & \\
\hline Formatted & \\
\hline Formatted & ... \\
\hline Formatted & \\
\hline Formatted & \\
\hline
\end{tabular}


TABLE 2: MEDIAN H-INDEX OF ACADEMIC UROLOGISTS IN NORTH AMERICA STRATIFIED BY ACADEMIC TITLE

\begin{tabular}{|c|c|c|c|c|c|c|}
\hline & $\begin{array}{c}\text { All } \\
\text { Physicians }\end{array}$ & $\begin{array}{c}\text { Clinical } \\
\text { Instructors }\end{array}$ & $\begin{array}{c}\text { Assistant } \\
\text { Professors }\end{array}$ & $\begin{array}{c}\text { Associate } \\
\text { Professors }\end{array}$ & Professors & $\begin{array}{l}\text { p- } \\
\text { value }\end{array}$ \\
\hline All Physicians & 11 & 5 & 6 & 13 & 29 & $<0.001$ \\
\hline \multicolumn{6}{|l|}{ AUA Section } & \multirow{9}{*}{$<0.001$} \\
\hline Mid-Atlantic & 9 & 3 & 6 & 11 & 25 & \\
\hline New England & 11 & 7 & 6 & 14 & 31 & \\
\hline New York & 10 & 12 & 6 & 14 & 26 & \\
\hline North Central & 15 & 3 & 8 & 14 & 33 & \\
\hline Northeastern & 12 & 7 & 6 & 16 & 26 & \\
\hline South Central & 10 & 4.5 & 5 & 10 & 27 & \\
\hline South Eastern & 11 & 8 & 4.5 & 13 & 27 & \\
\hline Western & 14 & 8 & 7 & 14.5 & 28 & \\
\hline \multicolumn{6}{|l|}{ Country } & \multirow{3}{*}{$<0.001$} \\
\hline United States & 11 & 5 & 6 & 13 & 29 & \\
\hline Canada & 17 & 7 & 9 & 17 & 29 & \\
\hline \multicolumn{6}{|l|}{ Gender } & \multirow{3}{*}{$<0.001$} \\
\hline Male & 14 & 5 & 6 & 14 & 29 & \\
\hline Female & 6 & 5 & 5 & 11 & 21 & \\
\hline \multicolumn{6}{|l|}{ Fellowship Trained? } & \multirow{3}{*}{$<0.001$} \\
\hline Yes & 13 & 5.5 & 7 & 14 & 29 & \\
\hline No & 7 & 3.5 & 3 & 7 & 27.5 & \\
\hline \multicolumn{6}{|l|}{ Fellowship Type } & \multirow{10}{*}{$<0.001$} \\
\hline Urologic Oncology & 17 & 8 & 11 & 19 & 37 & \\
\hline $\begin{array}{l}\text { Minimally Invasive } \\
\text { Surgery/Robotics }\end{array}$ & 18 & 4.5 & 11 & 20.5 & 27.5 & \\
\hline Endourology & 12 & 5 & 6 & 18 & 30 & \\
\hline $\begin{array}{l}\text { Female Pelvic } \\
\text { Medicine }\end{array}$ & 10 & 5 & 5 & 12 & 25 & \\
\hline $\begin{array}{l}\text { Reconstructive } \\
\text { surgery }\end{array}$ & 8 & 8 & 4.5 & 9 & 23.5 & \\
\hline Pediatric urology & 11 & 7 & 6 & 12 & 24 & \\
\hline Infertility/Andrology & 11 & 5.5 & 7 & 12.5 & 21 & \\
\hline Transplant & 12 & 2 & 5 & 11.5 & 20.5 & \\
\hline $\begin{array}{r}\text { Multiple } \\
\text { fellowships }\end{array}$ & 11 & 8 & 6 & 14 & 31 & \\
\hline
\end{tabular}


TABLE 3: MULTIVARIATE LOGISTIC REGRESSION ANALYSIS IDENTIFYING PREDICTORS OF H-INDEX GREATER THAN THE MEDIAN (H-Index > 11)

\begin{tabular}{|c|c|c|c|c|}
\hline \multicolumn{2}{|r|}{ Variable } & $\begin{array}{c}\text { Odds Ratio } \\
\text { (OR) }\end{array}$ & $\begin{array}{c}95 \% \text { Confidence } \\
\text { Interval }\end{array}$ & $p$-value \\
\hline \multirow{8}{*}{ AUA Section } & Mid-Atlantic & \multicolumn{3}{|c|}{ REFERENT } \\
\hline & New England & 1.68 & $0.99-2.83$ & 0.05 \\
\hline & New York & 1.40 & $0.86-2.26$ & 0.17 \\
\hline & North Central & 1.75 & $1.15-2.67$ & $<0.01$ \\
\hline & Northeastern & 1.15 & $0.64-2.07$ & 0.64 \\
\hline & South Central & 0.89 & $0.53-1.47$ & 0.64 \\
\hline & South Eastern & 1.11 & $0.72-1.70$ & 0.64 \\
\hline & Western & 1.56 & $1.02-2.40$ & 0.04 \\
\hline \multirow{2}{*}{ Country } & United States & \multicolumn{3}{|c|}{ REFERENT } \\
\hline & Canada & 1.33 & $0.76-2.32$ & 0.32 \\
\hline \multirow{2}{*}{ Gender } & Male & \multicolumn{3}{|c|}{ REFERENT } \\
\hline & Female & 0.34 & $0.24-0.48$ & $<0.01$ \\
\hline \multirow{2}{*}{$\begin{array}{l}\text { Fellowship } \\
\text { Trained }\end{array}$} & No & \multicolumn{3}{|c|}{ REFERENT } \\
\hline & Yes & 3.44 & $2.56-4.63$ & $<0.01$ \\
\hline \multirow{4}{*}{ Title } & Clinical Instructor & \multicolumn{3}{|c|}{ REFERENT } \\
\hline & Assistant Professor & 1.02 & $0.48-2.14$ & 0.96 \\
\hline & Associate Professor & 4.59 & $2.17-9.68$ & $<0.01$ \\
\hline & Professor & 30.17 & $13.88-65.54$ & $<0.01$ \\
\hline
\end{tabular}

